\title{
Problems and Countermeasures of Sustainable Development of Yan'an Comprehensive Energy Base
}

\author{
Jing Zhao* \\ School of Marxism \\ Xi'an University of Science and Technology \\ Xi'an, China
}

\author{
Xiao Chen \\ School of Marxism \\ Xi'an University of Science and Technology \\ Xi'an, China
}

\begin{abstract}
To promote the economic and social development of Yan'an, this paper uses investigation and empirical analysis to discuss sustainable development and utilization of Yan'an Energy. Based on the analysis of the construction basis and achievements of Yan'an Comprehensive Energy Base, and on the whole structure of the sustainable development system, obstacles and constraints of sustainable development are analyzed from resource, economic, social, ecological and environmental aspects. Finally, some policy suggestions such as expanding the industrial chain and developing alternative energy and industries are put forward. The innovations lie in drawing the new viewpoints of accelerating transition and development of Energy Industry, strengthening the construction of ecological environment.
\end{abstract}

Keywords-Yan'an Comprehensive Energy Base; Sustainable development; Resource; Economy; Society; Ecological environment

\section{INTRODUCTION}

Yan'an boasts abundant coal, oil and gas resources. After 100 years development of the petroleum industry, good foundation for the development of comprehensive energy industry base has been formed. In recent years, according to the major strategic plan of building a comprehensive energy base, local government insists on relying on the comprehensive advantages of energy resources, speeding up scientific and technological innovation and mechanism innovation, promoting the sustainable and healthy development of energy industry through energy transformation and high-end comprehensive utilization, extending the industrial chain and fostering new momentum of regional economic development. The construction of the national energy and chemical industry base in northern Shaanxi has made new breakthroughs in Yan'an, all of that further demonstrating the leading role of the energy industry in the economic and social development of Yan'an.

\section{COMPREHENSIVE ADVANTAGES OF ENERGY RESOURCES AND ACHIEVEMENTS OF ENERGY AND CHEMICAL INDUSTRY DEVELOPMENT IN YAN'AN}

Yan'an is rich in oil and natural gas resources, and its coal resources are very considerable. It has characteristic resource advantages of comprehensive energy and chemical industry. In recent years, Yan'an innovative energy development and utilization methods have promoted green, efficient and sustainable development of energy, realizing the transformation of resource advantages into economic advantages, and promoting the scientific development of the energy and chemical industry.

\section{A. Comprehensive advantages of energy resources}

Yan'an is located in the hinterland of the Loess Plateau in northern Shaanxi. It covers an area of 37,000 square kilometers and is rich in mineral resources. It has more than 10 proven mineral resources. Among them, the proven geological reserves of oil are 1.4 billion tons, the predicted reserves are 2.4 billion tons [1], the proven coal reserves are 11 billion tons and the proven reserves of natural gas are 2 trillion cubic meters [2]. The proven reserves of coalbed methane and shale gas are more than 300 billion cubic meters, and the predicted reserves of shale gas can reach 8-10 trillion cubic meters [3]. The abundant energy resources provide a solid material basis for the planning and construction of comprehensive energy and chemical industry bases in Yan'an City.

\section{B. Achievements in the development of energy and chemical industry}

Yan'an is the birthplace of China's petroleum industry. Yanchang Oil Mine is the mother of China's petroleum industry and has made great contributions to the Chinese revolution. At present, Yan'an has formed a production and processing capacity of tens of millions of tons and has become one of the main oil-producing areas in China. There are 24 petroleum development enterprises in Yan'an, of which 11 are from PetroChina Company Limited and Sinopec-group, and 13 from Yanchang Oilfield Joint Stock Company. By the end of 2016, 34147 high-standard clean and civilized wells have been built, with a completion rate of 90.1\% [1]. From 2005 to 2018, Yan'an local crude oil increased from 10 million tons to 15.2924 million tons, and crude oil processing capacity increased to 9.2396 million tons. Raw coal production increased from 5.374 million tons in 2003 to 51.12 million tons in 2018 [4].

The development of Yan'an energy and chemical industry has effectively promoted the rapid growth of the regional economy. In 2018, the gross domestic product (GDP) reached 
155.89 billion yuan, an increase of $9.1 \%$, and the local fiscal revenue reached 14.83 billion yuan, an increase of 5.6\% [5]. The economic living conditions of urban and rural residents have been improved. The per capita disposable income of urban residents increase of $8 \%$, and per capita disposable income of farmers increase of $9.2 \%$. At the same time, it promotes the development of related industries and the optimization of economic structure and enhances the selfdevelopment ability of Yan'an City.

\section{CONSTRAINTS ON THE CONSTRUCTION AND} DEVELOPMENT OF YAN'AN COMPREHENSIVE ENERGY BASE

\section{A. Constraints on the construction and development of Yan'an Comprehensive Energy Base}

The petroleum industry has long been the pillar industry of Yan'an City. Although the petroleum geological reserves have reached 1.38 billion tons, the remaining recoverable reserves are 170 million tons. In addition, the serious waste in the initial stage of resource exploitation leads to the serious shortage of petroleum resource blocks. The exploitation rate of petroleum resources has reached $80 \%$. The utilization degree of proven resources has exceeded the warning line. It is difficult to improve in the future [3].

\section{B. The ecological impact is intensified and environmental pollution is worrying}

Over the years, due to geological, aging pipelines and other reasons, while mining, the locals are also plagued by crude oil leakage pollution. During the development of coal resources, individual enterprises did not have any environmental protection procedures, which destroyed ecological environment and vegetation, and caused serious pollution of rivers. In May 2019, Yan'an City was publicly named by the Ministry of Ecology and Environment, because the quality of the water environment did not improve significantly, and even deteriorated significantly [6].

\section{Constraints on the construction and development of Yan'an Comprehensive Energy Base}

Because of thriving oil industry, the economy in Yan'an has shown signs of a typical resource-based economy and single industrial structure. At present, due to the decline in growth rate of the oil industry output, it is difficult for the oil industry as the main part of the industrial economic growth, and the city's industrial economic growth is facing severe challenges. Moreover, the development of the energy industry in Yan'an has been mainly depending on the expansion of number and size, and focusing only on the development of resources and rough processing, with a low degree of industrial correlation and short industrial chain. Resources consumptionbased traditional extensive mode of economic growth has not been radically changed so far.

\section{Lack of investment in science and technology and short of science and technology talent}

According to the relevant policies of the central and provincial governments, the three expenditures of science and technology in prefectures, cities and counties should reach more than $1 \%$ of the expenditure of the same level. However, the expenditure of Yan'an City is obviously low. For example, in Baota District, the three expenditures for science and technology at the municipal level were only 14.54 million yuan in 2015 , accounting for $0.58 \%$ of the fiscal expenditure at the same level [7]. In addition, scientific and technological talents in Yan'an are obviously insufficient both in quantity and quality. The contradiction between professional composition and actual demand is prominent. The scientific and technological front-line personnel are too old to adapt to the objective situation of scientific and technological and economic development.

\section{E. Constraints on the construction and development of Yan'an Comprehensive Energy Base}

The headquarters of Yan'chang Petroleum Group is far away from Yan'an, and the relationship between land and enterprise is increasingly alienated. Moreover, the construction of a modern enterprise system of Yanchang Petroleum Group and Yanchang Oilfield Joint Stock Company is relatively lagging, which brings institutional obstacles to the development of the petroleum industry. During the development of energy resources, there exist widely problems such as imperfect institutional mechanisms, insufficient certificate management and poor coordination of joint law enforcement.

\section{F. Labor underemployment and poverty problems are serious}

Up to the first quarter of 2019, the permanent population is $2,259,400$, the registered urban unemployment rate in Yan'an is $3.51 \%$ [8], the unemployed is 79,300 [9], the rural surplus labor resources are about 100,000, and the situation of urban re-employment and rural surplus labor transfer employment is very serious. The task of precise poverty alleviation has not yet been completed. The production and living of the poor and vulnerable groups, the construction of a social security system, employment and re-employment, disaster relief are arduous tasks.

\section{G. The financial burden is heavy and the pressure of regulating is increasingly large}

Yan'an fiscal revenue of 2016 was 13.05 billion yuan, reaching the lowest point in recent years [10], and this situation will be around for a long time to come. With the expansion of the scale of resource development, the city and county are also increasing their financial investment in environmental protection and governance, infrastructure construction, education and health. By the end of 2018, the city's government debt balance was 43.83 billion yuan [11]. With the arrival of the peak repayment period, the financial burden has gradually become heavy. The county's economic development is unbalanced, and the pressure on city-level fiscal regulation is increasing.

\section{$H$. North-South is in uneven development, the regional disparity is widening}

The county economic development is uneven. In 2016, Baota District of Yan'an City boasted the largest economic 
output of 22.514 billion yuan, but Huanglong County was the smallest of 1.397 billion yuan [12]. The difference between them was 21.117 billion yuan. The unbalanced economic development among the county has become a serious restriction factor for Yan'an to achieve leapfrog development.

\section{SUGGESTIONS ON SUSTAINABLE DEVELOPMENT OF YAN'AN COMPREHENSIVE ENERGY BASE}

\section{A. Adjust development scale, development alternative energy}

According to the occurrence conditions and requirements of sustainable development of local oil resources in Yan'an, the size of oil extraction and refining can't be expanded unlimitedly, and it must be regulated appropriately. A reasonable development scale should be determined to ensure the sustainable use and long-term stability. In the long run, the fossil energy will eventually be depleted, Yan'an Comprehensive Energy Base should make use of the support policy from the central government to develop green and renewable energy industry, develop and utilize the abundant wind energy and solar energy step by step in a planned way, so that Yan'an can truly become the energy industry base on which the country can rely for a long time.

\section{B. Improve the compensation mechanisms, strengthen environmental protection}

It is recommended that Shaanxi Province improve the compensation mechanism for resource development leading to the destruction of ecological environment during the sustainable development and utilization of Yan'an comprehensive energy, improve the market trading system of emission rights, guide enterprises to strengthen the management and comprehensive utilization of "three wastes", gradually make the environmental governance of mining areas enter a virtuous circle. Strictly enforce the law of environmental protection, establish the concept of "protection of the ecological environment is to protect productivity, improve the ecological environment is to develop productivity", implement environmental impact assessment, total pollutant discharge control, environmental target assessment and accountability system strictly to engage in changing from governance after pollution to pre-governance protection and to effectively change situation of "pollution first, treatment later, governance while pollution"; classify functional areas such as key development zones, restricted development zones and prohibited development zones according to the carrying capacity of environment. To protect the ecological environment through legislation, promote the sound and rapid development of the regional economy.

\section{Expand the industrial chain and develop alternative industries}

The sustainable development of Yan'an Comprehensive Energy Base must put structural adjustment in the first place, and constantly promote the upgrading of industrial structure to promote traditional industries emerging and pillar industry deepening. For this reason, the first is to take speeding up energy deep processing as an important and urgent task, to complete transformation from integration of exploration, extraction and refining to integration of exploration, extraction, refining and chemical transformation as soon as possible, and to focus on development of Yan'an oil coal chemical project to extend energy industry chain, and to build industrial economy relay points by making breakthrough on improving product added value; the second is to establish Yan'an continuation industry development fund, to seize opportunity to develop alternative industries such as mechanical working industry and fabricated metal products for supporting petroleum and petroleum chemical, ascendant green agriculture, culture, tourism, construction industries and so on, to work out a new way of mineral resource-based regional industrial restructuring and development.

\section{Build technological innovation system, strengthen talents team building}

First, a strategy of revitalizing the city through science and education under the guidance of the new development concept should be implemented, improve Yan'an scientific and technological progress policy as soon as possible, effectively increase investment in science and technology, and reward efforts of scientific and technological personnel to stimulate their enthusiasm and creativity. A special fund should be established for addressing Yan'an major scientific and technological issues, and technological problems restricting economic leaps and bounds. To integrate Yan'an existing technological resources effectively, local government should establish a cooperation mechanism and platform for interactions among governments, enterprises and scientific research institutions to accelerate the talent cultivation and improve Yan'an technology market, to respect and protect technology intellectual property and proprietary technology to speed up the process of the technology industry. Second, it must take a variety of measures to strengthen the ranks of technology and management talents, and fully mobilize the enthusiasm of the scientists and technicians.

\section{E. Improve enterprise system, build institutional mechanisms for coordinating development}

In the aspect of perfecting enterprise system, the process of extending the construction of modern enterprise system of Petroleum Group Company and oil field joint-stock company should be promoted actively. In the aspect of building the system mechanism of coordinated development between base and region, an equal dialogue mechanism between local and base-based enterprises should be established firstly to negotiate and solve ecological damage, loss of land by farmers and disputes over interests. The second is to establish a mechanism for the energy chemical industry to feedback the non-energy chemical industry and develop the equipment manufacturing industry matching the comprehensive energy industry.

\section{F. The reform tax system, adjust interest relations}

Firstly, it is suggested that the central government should further improve the resource tax system and increase the share proportion of Yan'an city and its county finance in tax revenue. Secondly, the nation should introduce environmental taxes to prevent pollution of the resource-based enterprises. In order to guarantee available financial resources for environmental 
governance in energy and chemical base, environmental taxes should be designed as central-local shared, and the bulk of taxes should be stay in the local areas. Thirdly, to further improve reimbursable usage system of exploration rights and mining rights system, increasing transfer income from local "two right price", the locals should be allowed to levy ecological environment compensation, energy price regulation fund and the Sustainable Development Fund to form a virtuous cycle of comprehensive energy base construction and local economic and social development.

\section{G. Coordinate contradictions between economy and society, emphasize economic development of south Yan'an}

Firstly, Yan'an local government should firmly hold that social development and economic development are equally important, to create overall planning of Yan'an social undertaking development, to increase government investment in social undertakings. Secondly, pay more attention to Yan'an rural development, increase financial investment in Yan'an rural social undertakings and infrastructure construction, speed up the process of construction of rural social security system, expand the coverage of farmers minimum living security, speed up establishment of rural pension system, strengthen the popularization of rural cooperative medical care, speed up construction of small towns, make Yan'an rich resources such as oil, coal benefit both urban and rural residents. Thirdly, pay more attention to the economic development of Yan'an southern counties. "Counties economic development special fund" should be established as soon as possible to ease the financial difficulties of counties in south Yan'an.

\section{V.CONCLUSION}

In May 2017, the National Energy Administration approved the implementation of the Yan'an Comprehensive Energy Base Development Plan, which requires that the development of Yan'an Comprehensive Energy Base must follow the general secretary Xi Jinping's energy development strategy of "four revolutions and one cooperation", implement the new development concept, build Yan'an into an important national regional energy security base, a demonstration zone for smart energy and comprehensive and coordinated development and utilization of energy resources.

The regional sustainable development system of Yan'an Comprehensive Energy Base is dynamic and complex. It is composed of four subsystems, including resources, economy, society and environment. The subsystems depend on, interact with and constrain each other. However, the development and utilization of energy resources in Yan'an are facing the constraints and problems, which have a certain impact and constraints on the construction and development of the comprehensive energy base in Yan'an.

The comprehensive energy base in Yan'an has a close relationship with regional environmental quality, economic and social structure and natural resources. Based on the constraints faced in the construction and development of Yan'an
Comprehensive Energy Base, the countermeasures are proposed, such as making development at the appropriate scale, promoting alternative energy sources development, improving compensation mechanisms, strengthening environmental protection, expanding the industrial chain, developing alternative industries, reforming the tax system, adjusting benefit distribution

\section{ACKNOWLEDGMENT}

This research was financially supported by project of Shaanxi Provincial Association of Social Science(2017C009), the project of Shaanxi Provincial Social Science Fund(2017A014), Key Construction Project of Demonstration Marxist College and Excellent Teaching and Scientific Research Team of Ministry of Education (18JDSZK038), Humanities and Social Science Talent Plan of Shaanx universities.

\section{REFERENCES}

[1] "Proposals and criticisms and opinions from representative of the First Session of the Fifth Yan'an People's Congress.No.96," http://www.yanan.gov.cn/gk/jyta/rdjy/303824.htm,October 2017. (In Chinese)

[2] "Provincial-municipal Co-construction Key Laboratory for Intelligent Processing of Energy Big Data in Shaanxi Province through Expert Demonstration,” http://www.yanan.gov.cn/xwzx/bmdtt/kji/350624.htm, November 2018. (In Chinese)

[3] "Yan'an, Shaanxi Provides a Great Plan for the Development of Comprehensive Energy Base,” http://www.zgdlrw.com/dlfz/13588. HTML, May 2019. (In Chinese)

[4] Yan'an Statistical Bureau, "the Achievements of Economic and Social Development in Yan'an on the 70th Anniversary of the Founding of New China," http://tj.yanan.gov.cn/index.php?m=content\&c=index\&a=show\&catid= 25\&id=8743, July 2019. (In Chinese)

[5] Yan'an People Government, “Government Work Report in 2019,” Yan’an: Yan’an People Government, 2019. (In Chinese)

[6] Zhang Junhong, "Industrial Economic Development Present Situation of Yan'an, Existing Problems and Countermeasure Research”, China Economist, pp.195-196+199, August 2014. (In Chinese)

[7] Baota District People Government, "Baota District has been identified as the second batch of innovative pilot areas in the province," http://www.yanan.gov.cn/xwzx/qxkx/194316.htm, March 2016.(In Chinese)

[8] Si Bohai, "the first quarter of the city's economic performance is encouraging.,’Yan’an Daily,April 2019(001). (In Chinese)

[9] Yan'an Statistical Bureau, "Statistical Communique of National Economic and Social Development of Yan'an City in 2018,' http://www.yanan.gov.cn/gk/tjxx/ndtj/382248.htm,April 2019. (In Chinese)

[10] Yan'an People Government, "Report on the Work of the Government in 2017,” Yan'an: Yan'an People Government, 2017. (In Chinese)

[11] Yan'an Finance Burea, “Local Government Debt of Yan'an Finance Bureau in 2018,” http://www.yanan.gov.cn/gk/czxx/zxzj/382386.htm, April 2019. (In Chinese)

[12] Yan'an Statistical Bureau, “Thoughts on the Unbalanced and Insufficient Problems of County Economic Development in Yan'an." http://www.yanan.gov.cn/gk/tjxx/tjfx/318517.htm, January 2018. (In Chinese) 